\title{
International randomised controlled trial of patient triggered ventilation in neonatal respiratory distress syndrome
}

\author{
J H Baumer
}

\begin{abstract}
Aim-To compare the effects of patient triggered ventilation (PTV) with conventional ventilation (IMV) in preterm infants ventilated for respiratory distress syndrome (RDS).

Methods-Nine hundred and twenty four babies from 22 neonatal intensive care units were assessed. They were under 32 weeks of gestation and had been ventilated for respiratory distress syndrome (RDS) for less than 6 hours within 72 hours of birth. The infants were randomly allocated to receive either PTV or IMV. Analysis was on an "intention to treat" basis. Death before discharge home or oxygen therapy at 36 weeks of gestation; pneumothorax while ventilated; cerebral ultrasound abnormality nearest to 6 weeks; and duration of ventilation in survivors were the main outcome measures.
\end{abstract}

Results-There was no significant difference in outcome between the two groups. Unadjusted rates for death or oxygen dependency at 36 weeks of gestation were $47.4 \%$ and $48.7 \%$, for PTV and IMV, respectively; for pneumothorax these were $13.4 \%$ and $10.3 \%$; and for cerebral ultrasound abnormality nearest to 6 weeks these were $35.4 \%$ and $36.9 \%$. Median duration of ventilation for survivors in both groups was 6 days. Overall, 79\% of babies received only their assigned ventilation. PTV babies were more likely to depart from their intended ventilation $(27 \%$ vs $15 \%)$. The trend towards higher pneumothorax rates with PTV occurred only in infants below 28 weeks of gestation $(\mathbf{1 8 . 8 \%}$ vs $\mathbf{1 1 . 8 \%})$.

Conclusions-There was no observed benefit from the use of PTV, with a trend towards a higher rate of pneumothorax under 28 weeks of gestation. Although PTV has a similar outcome to IMV for treatment of RDS in infants of 28 weeks or more gestation, within 72 hours of birth, it was abandoned more often. It cannot be recommended for infants of less than 28 weeks' gestation with the ventilators used in this study. (Arch Dis Child Fetal Neonatal Ed 2000;82:F5-F10)

Keywords: patient triggered ventilation; respiratory distress syndrome; intermittent positive pressure ventilation
Greenough et $a l^{1}$ observed that active expiration against ventilator inflation was associated with a high risk of pneumothorax and that this could be prevented by selective paralysis. It is not always possible clinically to identify infants actively expiring against the ventilator, ${ }^{2}$ and paralysis has several adverse effects, including the prolongation of ventilation and fluid retention. This led to attempts to achieve synchronous ventilation, with matching of phase and rate of the infant's and the ventilator's respiratory cycles. These have included ventilating infants at fast rates, ${ }^{3}$ setting the ventilator to the infant's inspiratory and expiratory times, ${ }^{4}$ and patient triggered ventilation (PTV).

PTV aims to provide phase and rate matched ventilation such that ventilator inflation only occurs during the infant's inspiratory phase and does not extend into its period of expiration. Short term benefits from PTV have been shown in randomised controlled trials involving small numbers of infants. These include improvement in oxygenation, ${ }^{5-7} \mathrm{im}-$ proved $\mathrm{CO}_{2}$ elimination, ${ }^{6}$ increased minute volume, ${ }^{7}$ shorter time to extubation, ${ }^{8-10}$ decreased work of breathing, ${ }^{11}{ }^{12}$ decreased cerebral blood flow velocity variability ${ }^{13}$ and decreased beat to beat blood pressure fluctuations. ${ }^{12}$ It is also claimed that PTV is less stressful for babies and produces a smoother course of ventilation. A reduction in plasma adrenaline concentrations in babies changed from intermittent mandatory ventilation (IMV) to PTV has been shown in one study. ${ }^{14}$

Two major alternative modes have been tried-namely, PTV where every patient inspiration triggers a ventilator breath - and synchronised intermittent mandatory ventilation (SIMV), where each breath triggers the ventilator only if it falls within a time window set by the operator. One prospective, randomised controlled trial compared SIMV with slow rate mandatory ventilation and included the outcomes of pneumothorax and chronic lung disease of prematurity. ${ }^{15}$ Despite the finding of a significantly lower rate of oxygen dependence at 36 weeks of gestation in infants under $1 \mathrm{~kg}$ birthweight on SIMV, there was no significant effect on mortality or pneumothorax rates.

Clinical experience of using the SLE 2000, a jet ventilator capable of trigger ventilation using an airway pressure sensor, led to policies 
for setting up, adjusting, and weaning babies from PTV. This ventilator had already proved capable of ventilating premature infants with respiratory distress syndrome from birth to extubation. ${ }^{16}$ This prompted a multicentre open randomised controlled trial to investigate the effects of PTV compared with IMV in preterm infants ventilated for respiratory distress syndrome (RDS). Currently available neonatal trigger ventilators using an airway sensor were used.

\section{Methods}

The study was designed to compare PTV and IMV in RDS in respect of four main outcomes: hospital mortality or the need for oxygen treatment at 36 weeks of gestation; pneumothorax; cerebral ultrasound abnormality nearest to 36 weeks of gestation; and the duration of ventilation in survivors.

Sample size predictions were based on the rates of pneumothorax observed in all controlled trials, reporting rates in infants treated with surfactant. ${ }^{17-26}$ Rates varied from 5 to $36 \%$, with a mean of $14.5 \%$. A sample size of 1760 gave an $80 \%$ power of detecting a difference between rates of $17 \%$ and $12 \%$, regarded as significant at the $5 \%$ level in a two tailed test of proportions. These differences were the smallest that could reasonably be considered of clinical importance. The rate of the other primary outcome - survival to discharge home, having been oxygen independent from 36 weeks of gestation - was estimated at $80 \%$. The sample size should detect a difference between rates of $82 \%$ and $75 \%$, with a power of $95 \%$, using a two tailed test and significance at the $5 \%$ level. In March 1996, after the trial had continued for three years, it became clear that the sample size was not achievable within the funded time. It was agreed that the closing date for recruitment should be set to achieve a sample size of around 1000 babies. The sample size actually achieved when recruitment closed after 4 years 7 months gave an $80 \%$ power to detect pneumothorax rate differences of $18.5 \%$ and $12 \%$, and oxygen free survival rates of $82 \%$ and $74 \%$.

The study included 22 neonatal intensive care units who had at least one suitable trigger ventilator (SLE 2000 or Dräger babylog 8000) and who were willing to randomly allocate babies to PTV or IMV. Written agreed guidelines on the ventilation techniques were available in participating units. Collaborators were instructed to start babies on PTV with inspiratory times of between 0.2 and $0.25 \mathrm{sec}$ onds, the ventilator set to trigger at each inspiratory effort and a backup rate of 35 breaths a minute. Those receiving IMV had ventilator rates set initially at between 40 and 65 breaths a minute, with instructions to increase the rate as required, and initial inspiratory times between 0.2 and 0.6 seconds. In both modes of ventilation inspiratory and expiratory pressures and oxygen concentrations were chosen by the attending clinicians. In PTV mode collaborators were instructed to wean by progressively reducing peak inspiratory pressure to a minimum of 8 to $10 \mathrm{~cm} \mathrm{H}_{2} \mathrm{O}$.
In IMV mode, weaning was accomplished by reducing peak inspiratory pressure to a minimum of $16 \mathrm{~cm} \mathrm{H}_{2} \mathrm{O}$ and then by reducing the rate.

Babies were eligible to be entered if they were less than 32 completed weeks of gestation, required ventilation within 72 hours of birth, and had been ventilated for no more than 6 hours at randomisation. A ventilator capable of delivering PTV was required, and the clinical and radiological features had to be compatible with RDS. Babies were excluded if there was clinical or radiological evidence of a major congenital malformation or inhalational pneumonitis at trial entry.

The mode of ventilation was randomly allocated by telephone, according to a written protocol, after oral or written parental consent had been obtained. Participating centres were asked to record the birthweight, gestation, and clinical severity CRIB (clinical risk index for babies) score ${ }^{27}$ together with the reason(s) for non-randomisation of all otherwise eligible infants who were not entered into the trial. Within each centre, randomisation was performed in blocks to ensure a similar distribution of babies in each arm of the study as it proceeded.

Infants were required to receive the form of ventilation to which they were assigned from birth to final extubation. Trial entry was stratified by centre. Clinicians were allowed the discretion to change the baby from the assigned mode of ventilation on clinical grounds, although they were discouraged from doing so. The main reason for, and date of altering, the mode of ventilation was recorded.

Local research ethics committee approval was obtained in all participating centres.

Clinical information was collected on antenatal steroid use, mode of delivery, postnatal surfactant administration, whether there was a multiple birth, the sex, birthweight, and gestation of the baby, CRIB score, and details of ventilation, outcomes, departure from assigned mode of ventilation and complications and cause of death. A trial report form was completed at the time of discharge from hospital or transfer to another unit. Two different individuals created separate computer databases from these report forms, and each was checked for completeness and accuracy.

A cranial ultrasound scan was required at 6 weeks of postnatal age, or as near to that date as possible before discharge home in all infants. Ventricular size was assessed using the ventricular index of Levene et al. ${ }^{28}$ The scan was interpreted by the most experienced doctor in each unit. The scan was reported by a doctor who was usually unaware of the treatment assignment. The scan was scored separately for each hemisphere as follows. Haemorrhage (0 no haemorrhage, 1 localised subependymal or choroidal haemorrhage, 2 intraventricular haemorrhage, 3 parenchymal haemorrhagic lesion); ventricular size ( 0 no dilatation, 1 dilatation less than $4 \mathrm{~mm}$ above the 97 th centile, 2 hydrocephalus greater than $4 \mathrm{~mm}$ above 97 th centile); parenchymal cysts (0 no cysts, 1 porencephalic cyst, 2 cystic leucomalacia). 
Eligible babies

1378

Reason for nonrandomisation known

\section{3}

Randomised

924
465 allocated to PTV

460 recieved PTV at some time
459 allocated to IMV

455 recieved IMV at some time

\begin{tabular}{|c|c|c|}
\hline 463 & $\begin{array}{l}\text { Known whether departed from } \\
\text { assigned ventilation }\end{array}$ & 458 \\
\hline 339 & Recieved only assigned ventilation & 390 \\
\hline 465 & Reached primary endpoint* & 459 \\
\hline 465 & Analysed at primary endpoint & 459 \\
\hline 423 & Cerebral ultrasound scan available & 422 \\
\hline 464 & Analysed for pneumothorax & 458 \\
\hline
\end{tabular}

* death or discharge from hospital

Figure 1 Trial profile. effects on the outcomes were seen, a logistic regression model was used to look for a possible association with type of ventilator, taking into account other significant factors-namely, CRIB score and centre.

Analysis was by an intention to treat basis. It was agreed that only differences in the key outcome of survival to discharge without oxygen dependence at 36 weeks, significant at the $0.15 \%$ level $(\mathrm{p}<0.0015)$ using a two tailed test, would stop recruitment to the trial, to avoid misleading deductions being drawn from early results. ${ }^{29} \mathrm{~A}$ confidential interim analysis of the study was carried out once the first 400 babies had been recruited, and presented to the independent data monitoring committee which recommended continuing the trial.

\section{Results}

Overall, 924 babies were recruited to the trial. One additional infant was randomly assigned, but immediately recognised as not being eligible: no information was collected and the infant was not included in analysis. Two babies assigned to IMV were subsequently realised to be 32 and 33 weeks of gestation; they were analysed as though eligible. Three infants died with congenital abnormalities not evident at randomisation. One each had aortic stenosis, congenital cardiomyopathy, and hypoplastic left heart syndrome. They were all analysed according to their assigned mode of ventilation. Randomisation details are shown in fig 1 .

Information was available on 1378 eligible babies born at participating centres during the period of collaboration. The most common stated reasons for non-randomisation were: no consent sought for any reason (149 babies), accidental oversight ( 88 babies), no ventilator available for randomisation (52 babies), and parental refusal ( 52 babies). There was no significant difference in birthweight or gestation between babies who were not randomised and those who were. However, non-randomised babies had a significantly higher illness severity score (mean (SD) CRIB score 8.1 (5.6) vs 6.1 (4.2); $t=6.26, \mathrm{p}<0.001)$.

The babies assigned to the two modes of ventilation were very comparable at trial entry (table 1).

Overall, 192 infants (21\%) departed from their assigned mode of ventilation at some point (fig 1). There was a significantly higher rate of departure from the assigned mode of ventilation in babies receiving PTV (124/463 $(27 \%)$ vs 68/458 (15\%), $\left.\chi^{2} 19.2, \mathrm{p}<0.0001\right)$. Forty five babies randomised to PTV had their mode of ventilation changed because of failure to trigger the ventilator. Babies receiving PTV who departed from their assigned mode of ventilation were significantly more likely to do so within the first 72 hours than those on IMV $\left(60 / 114(53 \%)\right.$ vs $16 / 62(26 \%), \chi^{2} 10.7$, $\mathrm{p}<0.005)$.

The major outcomes of the study are shown in table 2. There was no significant difference for any of the outcomes between the two treatment groups. Odds ratios (95\% confidence limits) for death or chronic lung disease, pneu- 
Table 1 Patient matching

\begin{tabular}{|c|c|c|}
\hline & $\begin{array}{l}\text { Trigger } \\
\text { number (\%) }\end{array}$ & $\begin{array}{l}\text { Conventional } \\
\text { number (\%) }\end{array}$ \\
\hline \multicolumn{3}{|l|}{ Antenatal steroids } \\
\hline None & $126(27.3)$ & $121(26.5)$ \\
\hline$<24$ hours & $121(26.2)$ & $109(23.9)$ \\
\hline$>24$ hours & $215(46.5)$ & $226(49.6)$ \\
\hline \multicolumn{3}{|l|}{ Type of delivery } \\
\hline Vaginal & $206(44.3)$ & $218(47.5)$ \\
\hline Caesarean section & $259(55.7)$ & $241(52.5)$ \\
\hline Singletons & $361(77.6)$ & $340(74.2)$ \\
\hline Multiple births & $104(22.4)$ & $118(25.8)$ \\
\hline Firstborn & 41 & 56 \\
\hline Second born & 57 & 57 \\
\hline Third born & 6 & 5 \\
\hline Twins & 83 & 104 \\
\hline Triplets & 21 & 14 \\
\hline Quads & 0 & 1 \\
\hline \multicolumn{3}{|l|}{ Place of delivery } \\
\hline Inborn & $399(86.2)$ & $399(87.1)$ \\
\hline Outborn & $64(13.8)$ & $59(12.9)$ \\
\hline \multicolumn{3}{|l|}{ Sex } \\
\hline Male & $265(57.0)$ & $271(59.0)$ \\
\hline Female & $200(43.0)$ & $188(41.0)$ \\
\hline \multicolumn{3}{|l|}{ Surfactant } \\
\hline No & $36(7.7)$ & $29(6.3)$ \\
\hline Yes & $429(92.3)$ & $430(93.7)$ \\
\hline \multicolumn{3}{|l|}{ Birthweight (g) } \\
\hline Mean (SD) & $1097(327)$ & $1123(345)$ \\
\hline Number & 465 & 459 \\
\hline \multicolumn{3}{|l|}{ Gestation (weeks) } \\
\hline Mean (SD) & $27.8(2.0)$ & $27.8(2.1)$ \\
\hline Number & 465 & 459 \\
\hline \multicolumn{3}{|l|}{ CRIB score } \\
\hline Mean (SD) & $6.2(4.1)$ & $6.0(4.2)$ \\
\hline Number & 464 & 456 \\
\hline \multicolumn{3}{|l|}{ Ventilator used } \\
\hline SLE 2000 & 411 & 321 \\
\hline Dräger babylog 8000 & 52 & 56 \\
\hline Sechrist & 0 & 57 \\
\hline Other & 2 & 25 \\
\hline
\end{tabular}

mothorax, and ultrasound abnormality were 0.95 (0.73 to 1.23 ), 1.35 (0.90 to 2.02 ), 0.94 (0.71 to 1.24$)$.

The time to extubation in survivors was not significantly different using the logrank test, with death as a censored event $(p=0.67)$.

In a posthoc analysis, pneumothoraces were more commonly seen in infants below 28 weeks receiving PTV rather than IMV (40/213, $18.8 \%$ vs $22 / 186,11.8 \%$, respectively; odds ratio $1.72,95 \%$ confidence intervals 0.98 to 3.02). Among infants of 28 weeks and above, pneumothoraces occurred in $22 / 250,8.7 \%$ of those receiving PTV and in $25 / 272,9.2 \%$ of those receiving IMV (odds ratio 0.95, 95\% confidence intervals 0.52 to 1.74 ). This difference in effect by gestation was not seen for the other outcomes.

The rates of intracerebral parenchymal haemorrhage in the PTV and IMV groups were $9.4 \%$ and $7.1 \%$, and of cystic leucomalacia $2.4 \%$ and $2.9 \%$, respectively.

Table 2 Outcomes

\begin{tabular}{|c|c|c|}
\hline & $\begin{array}{l}\text { Trigger No } \\
(\%)\end{array}$ & $\begin{array}{l}\text { Conventional } \\
\text { No }(\%)\end{array}$ \\
\hline \multicolumn{3}{|l|}{ Death or chronic lung disease } \\
\hline Yes & $219(47.4)$ & $220(48.7)$ \\
\hline No & 243 & 232 \\
\hline \multicolumn{3}{|l|}{ Pneumothorax } \\
\hline Yes & $62(13.4)$ & $47(10.3)$ \\
\hline No & 402 & 411 \\
\hline \multicolumn{3}{|c|}{ Ultrasound abnormality to nearest 6 weeks } \\
\hline Yes & $146(34.5)$ & $154(36.5)$ \\
\hline No & 277 & 268 \\
\hline $\begin{array}{l}\text { Median interquartile rang } \\
\text { ventilation duration in } \\
\text { survivors (days) }\end{array}$ & $6,(3-15)$ & $6,(3-15)$ \\
\hline
\end{tabular}

One hundred and six deaths occurred in the PTV group (23\%) and 86 in the IMV group (19\%). Most deaths (92 of 192) occurred in the first week. Post mortem examinations were undertaken in $50(26 \%)$. The main cause of death was respiratory failure in 111 infants. The second commonest cause of death was intraventricular haemorrhage in 16 babies.

The most frequent complications recorded were septicaemia in 181 (15 died), patent ductus arteriosus in 163 (no directly attributable deaths), and necrotising enterocolitis in 85 infants (10 died). There was no significant difference in the rate of any complication between the two groups. Forty two babies had positive blood cultures in the first 72 hours, the most common organisms isolated being Staphylococcus epidermidis, group B streptococcus, Escherichia coli, Haemophilus influenzae and Staphylococcus aureus.

One hundred and twenty babies in three centres were randomly assigned to their type of ventilator, and no significant differences in outcome by type of ventilator were seen. In a logistic regression model, there was a non-significant trend towards a higher rate of pneumothorax (odds ratio 1.74, 95\% confidence intervals 0.89 to 3.39) and death or chronic lung disease (odds ratio 1.34, 95\% confidence intervals 0.84 to 2.15), and a non-significant trend towards a lower rate of abnormal ultrasound scan around 6 weeks (odds ratio $0.69,95 \%$ confidence intervals 0.41 to 1.15 ), in infants ventilated with the Dräger babylog 8000 .

\section{Discussion}

There was no observed benefit from the use of PTV, as practised in this trial. The $95 \%$ confidence limits are such that any effect not seen because of type 2 errors would be small. There was a non-significant trend towards a higher rate of pneumothorax in the trigger ventilated babies, which appeared to be confined to infants under 28 weeks of gestation, with an upper $95 \%$ confidence limit for the odds ratio of 2 .

Using the ventilators in this study, PTV may not produce any greater synchrony than IMV; synchrony might have occurred more frequently in PTV mode but without benefit; and synchronous ventilation may only be achievable in infants with mild RDS or in more mature infants. The SLE 2000 ventilator used in most infants is said $^{30}$ to be prone to auto-triggering (spontaneous ventilator inflations untriggered by the infant) at the highest sensitivity setting. Participating clinicians were aware of this possibility, but the phenomenon is not easy to detect clinically. A recent study ${ }^{31}$ showed a high rate of asynchrony in infants of 28 weeks or less of gestation with the two main ventilators used in trigger mode in this study. At least some of the babies with the rates of mandatory ventilation used in this study will have had ventilation that was synchronous with the ventilator through a process of entrainment. ${ }^{32} 33$

The shorter inspiratory times permitted in PTV mode might have resulted in reduced tidal volumes. ${ }^{34}$ However, in previous studies of 
triggered ventilation, tidal volumes have not been compromised by inspiratory times within the range used in this study. ${ }^{313536}$ One study ${ }^{31}$ found a significant reduction in asynchrony rates (triggered inflation extending into expiration) with shorter inspiratory times in the VIP Bird ventilator, suggesting that short inspiratory times are beneficial in PTV mode.

The performance of different trigger ventilators and of different trigger sensors varies, and there is no agreed optimum system. ${ }^{37-39}$ However, the two neonatal ventilators used are both said to have short trigger delays averaging less than 100 milliseconds, and to be sufficiently sensitive to pick up most infant breaths, at least in more mature infants. ${ }^{404}$

In a study of 10 infants of 28 weeks of gestation or less Dimitriou et $a l^{\beta 1}$ found that a significantly higher proportion of breaths triggered the ventilator using the Dräger babylog 8000 ventilator compared with the SLE 2000. Most infants in this study were ventilated with the SLE 2000. Although the study design allowed randomisation between airway pressure triggered and airflow triggered ventilators, very few centres had both ventilators available. The magnitude of the non-significant associations with three outcomes in a logistic regression model would require a study involving over 2000 babies to achieve sufficient power to establish whether these differences are real, but emphasises the importance of considering the effects of different ventilator performance. The associations of mode of ventilation with the main outcomes were not altered by the use of this logistic regression model, confirming that the study conclusions are robust.

The results of this study are similar to those of the one multicentre randomised controlled trial of SIMV compared with conventional ventilation $^{15}$ in 327 infants. The study involved multiple analyses, raising the possibility of type I errors. Despite a significant reduction in the duration of ventilation with SIMV in infants of over $2 \mathrm{~kg}$, and in oxygen dependency at 36 weeks of gestation in infants less than $1 \mathrm{~kg}$, there was no overall difference in the rate of mortality, pneumothoraces, or of severe intraventricular haemorrhage. The conventional mode of ventilation used in the study involved rates of around 30 breaths per minute, which some would consider suboptimal. ${ }^{42}{ }^{43}$

Infants receiving IMV in this study were started on rates of 60 breaths a minute or above in all but one centre, and maintained above this rate except during weaning. The backup rate in the PTV group was set at a level designed ${ }^{44}$ to minimise untriggered breaths while maintaining ventilation in apnoeic babies. The written guidelines permitted clinicians to increase this backup rate in persistent apnoea, thus avoiding slower rates of ventilation in such circumstances. It is therefore unlikely that differences in ventilator rate between the two modes of ventilation contributed to the outcome.

Did the clinicians in the trial apply the technique of triggered ventilation correctly? Many centres already had experience of PTV. The method had been developed from observations of preterm infants on PTV and from short term randomised controlled trials involving small numbers of infants. The trial co-ordinator visited each unit before randomisation started and briefed both medical and nursing staff in the technique. Written protocols with details of both techniques of ventilation were available at each centre throughout the study. As some units were randomising infants for 4 years any initial difficulties should have been resolved within that time. However, other treatments given to infants might have interfered with successful triggering. The initial experience of PTV in one centre ${ }^{16}$ reported a lower rate of pneumothoraces than that achieved in the trial. At that time, theophylline was used routinely in trigger ventilated babies, and morphine was used very infrequently. These practices had changed by the time the trial started. Both theophylline and morphine use are likely to influence the baby's respiratory efforts and therefore the successful achievement of synchrony in trigger mode.

PTV was abandoned more often than IMV. This difference was partly explained by the infants whose mode of ventilation was changed because of failure to trigger the ventilator. The most premature babies and those who subsequently died were more likely to have their mode of ventilation changed. It is not surprising that infants had a change in their mode of ventilation when their survival was in doubt. However, most babies who subsequently died received only their assigned mode of ventilation. There was no significant difference in any of the outcomes among infants who received only their assigned mode of ventilation.

In conclusion, there was no convincing evidence of a beneficial effect of a policy of using PTV in preterm infants with RDS on rates of death and chronic lung disease, pneumothorax or cerebral ultrasound abnormality. The duration of ventilation was identical. With these results, together with the trend towards a higher rate of pneumothorax, it might be prudent to avoid PTV in infants less than 28 weeks who ventilated for RDS using either the SLE 2000 or Dräger babylog 8000 until the results of further studies become available.

Trial collaborators (numbers are totals of babies recruited by each centre)

JH Baumer, M Hunt Derriford Hospital, Plymouth 136 M Quinn, A Busfield. Royal Devon \& Exeter Hospital 135 PM Barnes, J McFarlane. Al Corniche Hospital, Abu Dhabi 106 HD Dellagrammaticas, C Christodoulou. Aglaia Kyriakou Children's Hospital, Athens, Greece 88

P Daish, T Pollard. Northampton General Hospital 72

D McMillan, L Bourcier. Foothills Hospital, Calgary, Alberta, Canada 61

J Smyth, J Hume. Royal Berkshire Hospital, Reading 61

I Verber, L Clarke. North Tees General Hospital, North Tees 49 RD Clifford, S Townsend. Dorset County Hospital, Dorchester 38 $M$ Watkinson, M Cebula. Birmingham Heartlands Hospital 34 EE Shoo, S Appleton. Tameside General Hospital 29 MP Ward EE Shoo, S Appleton. Tameside General Hospital 29 MP Ward Platt, M Smith. Royal Victoria Hospital, Newcastle upon Tyne 26 JWT Benson, D Hatton. Queens Park Hospital, Blackbur
R Jones, C Burden. Wexham Park Hospital, Slough 14 AJ Bradbury, L Goodwin. Wythenshawe Hospital, Manchester 13 AJ Bradbury, L Goodwin. Wythenshawe Hospital, Manchester 13 $\mathrm{CH}$ Cheethan
Wycombe 13

Wycombe 13
R Brown, Z Fazilahmed. Stoke Mandeville Hospital, Aylesbury 11 $\mathrm{R}$ Brown, Z Fazilahmed. Stoke Mandeville Hospita
$\mathrm{R}$ Welch, C Smith. Royal Shrewsbury Hospital 8 MP White, J Sangster. Southern General Hospital, Glasgow 6 R Miles, C Nunns. Hinchingbrooke Hospital 5

A Shah, C Harper. North Middlesex Hospital, London 4

D Robinson, M Chan. King George Hospital, Goodmayes, Essex 1

The paper was written with assistance from the trial collaborators. The trial was funded by a grant of 97000 from the NHS R\&D Directorate.

SLE Ltd provided a desktop computer for research coordinator. 
1 Greenough A, Wood S, Morley C J, Davis J A. Pancuronium prevents pneumothoraces in ventilated premature babies who actively expire against positive pressure inflation. Lancet $1984 ; \mathbf{i}: 1-4$.

2 Greenough A, Greenall F. Observation of spontaneous respiratory interaction with artificial ventilation. Arch Dis Child 1988;63:168-71

3 Greenough A, Morley CJ, Pool J. Fighting the ventilator are fast rates an effective alternative to paralysis? Early Hum Dev 1986;13:189-94.

4 Field DJ, Milner AD, Hopkin IE. Manipulation of ventilator settings to prevent active expiration against positive
pressure ventilation. Arch Dis Child 1985;60:1036-40.

5 Mehta A, Callan K, Wright B M, Stacey T E. Patienttriggered ventilation in the newborn. Lancet 1986;ii:1719.

6 Greenough A, Hird MF, Chan V. Airway pressure triggered ventilation for preterm neonates. $f$ Perinat Med 1991;19:471-6.

7 Servant G, Nicks JJ, Donn SM, Bandy KP, Lathrop C, Dechert RE. Feasibility of applying flow-synchronized ventilation to very low birthweight infants. Respir Care 1992;37:249-53.

8 Chan V, Greenough A. Randomised controlled trial of weaning by patient triggered ventilation or conventional ventilation. Eur $\mathcal{F}$ Pediatr 1993;152:51-4

9 Visveshwara N, Freeman B, Peck M, Caliwag W, Shook S, Rajani K B. Patient-triggered synchronized assisted ventilation of newborns; report of a preliminary study and three years' experience. $\mathcal{F}$ Perinatol 1991;XI:347-54.

10 Donn SM, Nicks JJ, Becker MA. Flow-synchronized ventilation of preterm infants with respiratory distress syndrome. F Perinatol 1994;14:90-4.

11 Jarreau P-H, Moriette G, Mussat P, et al. Patient-triggered ventilation decreases the work of breathing in neonates. Am $\mathcal{7}$ Respir Crit Care Med 1996;153:1176-81.

12 Hummler H, Gerhardt T, Gonzalez A, Claure N, Everett R, Bancalari E. Influence of different methods of synchronized mechanical ventilation on ventilation, gas exchange, nized mechanical ventilation on ventilation, gas exchange, patient effort, and blood pressure fluctuations in pr

13 Govindaswami B, Heldt GP, Bernstein G, Bejar R. reduction in cerebral blood flow velocity $(\mathrm{CBFV})$ variability in infants $<1500 \mathrm{~g}$ during synchronized ventilation
(SIMV). Pediatr Res 1993;33:213A.

14 de Boer RC, Ansari N, Quinn MW, Baumer JH. Stress response and mode of ventilation in preterm infants. Arch Dis Child Fetal Neonatal Ed 1998;78:F195-8.

15 Bernstein G, Mannino FL, Heldt GP, et al. Randomized multicenter trial comparing synchronized and conventional intermittent mandatory ventilation in neonates. $f$ Pediatr 1996;128:453-63.

16 de Boer R, Jones A, Ward PS, Baumer JH. Long term trigger ventilation in respirat

A, Jarvenpaa A-L, et al. Exogenous Gallman M, Merritt T A, Jarv human surfactant for treatment of severe respiratory distress syndrome: a randomized prospective clinical trial. 7 Pediatr 1985;106:963-9.

18 Morley C J. Surfactant substitution in the newborn by application of artificial surfactant. $\mathcal{f}$ Perinat Med $1987 ; 15: 4$

19 Gitlin J D, Soll R F, Parad R B, et al. Randomized controlled trial of exogenous surfactant for the treatment of hyaline membrane disease. Pediatrics 1987;79:31-7.

20 Horbar J D, Soll R F, Sutherland J M, et al. A multicenter randomized, placebo-controlled trial of surfactant therapy for respiratory distress syndrome. $N$ Engl f Med 1989;320:959-65.

21 Collaborative European Multicenter Study Group. Surfactant replacement therapy for severe neonatal respiratory distress syndrome: an international randomized clinical trial. Pediatrics 1988;82:683-91.
22 Konishi M, Fujiwara $\mathrm{T}$, Naito $\mathrm{T}$, et al. Surfactant replacement therapy in neonatal respiratory distress replacement therapy in neonatal re
syndrome. Eur $\mathcal{F}$ Pediatr 1988;147:20-5.

23 Charon A, Taeusch H W, Fitzgibbon C, Smith G B, Treves $S$ T, Phelps D S. Factors associated with surfactant treatment response in infants with severe respiratory distress syndrome. Pediatrics 1989;83:348-54.

24 Long W, Corbet A, Cotton R, et al. A controlled trial of synthetic surfactant in infants weighing $1250 \mathrm{~g}$ or more with respiratory distress syndrome. $N$ Engl ${ }^{\prime} \quad \mathrm{Med}$ 1991;325:1696-703.

25 McCord F B, Curstedt T, Halliday H L, McClure G, Reid M, Robertson B. Surfactant treatment and incidence of intraventricular haemorrhage in severe respiratory distress syndrome. Arch Dis Child 1988;63:10-16.

26 Lang M J, Reddy N S, Kurth C G, Merritt T A, Hall R T. Human surfactant replacement therapy for severe hyaline membrane disease in very low birthweight infants. Pediatr Res 1989;25:318A.

27 The International Neonatal Network. The CRIB (clinical risk index for babies) score: a tool for assessing initial neonatal risk and comparing performance of neonatal natal risk and comparing performance

28 Levene M I. Measurement of the growth of the lateral ventricles in preterm infants with real-time ultrasound. Arch Dis Child 1981;56:900-4.

29 Peto R, Pike M C, Armitage P, et al. Design and analysis of randomized clinical trials requiring prolonged observation of each patient. Br f Cancer 1976;34:585-612

30 Heldt G, Bernstein G. Patient-initiated mechanical ventilation. In: Boynton BR, Carlo WA, Jobe AH, eds. New therapies for neonatal respiratory failure: a physiologic approach. New York: Cambridge University Press, 1994:166.

31 Dimitriou G, Greenough A, Laubscher B, Yamaguchi N. Comparison of airway pressure-triggered and airflowtriggered ventilation in very immature infants. Acta Paediatrica 1998;87:1256-60.

32 South M, Morley CJ. Synchronous mechanical ventilation of the neonate. Arch Dis Child 1986;61:1190-5.

33 Bignall S, Dixon P, Quinn C, Kitney R. Monitoring interactions between spontaneous respiration and mechanical inflations in preterm ned 1997:25:545-53.

34 Field D, Milner AD, Hopkin IE. Inspiratory time and tidal volume during intermittent positive pressure ventilation. Arch Dis Child 1985;60:259-6

35 Upton CJ, Milner AD, Stokes GM. The effects of changes in inspiratory time on neonatal triggered ventilation. Eur $\mathcal{f}$ Pediatr 1990;149:648-50.

36 Hird MF, Greenough A. Comparison of triggering systems for neonatal patient triggered ventilation. Arch Dis Child 1991;66:426-8.

37 Donn SM, Sinha SK. Controversies in patient-triggered ventilation. Clin Perinatol 1998;25:49-61.

38 Laubscher B, Greenough A, Kavadia V. Comparison of body surface and airway triggered ventilation in extremely premature infants. Acta Paediatrica 1997;86:102-4.

39 Bernstein G, Heldt GP, Mannino FL. Body surface and airway triggered ventilation in extremely premature infants. Acta Paediatrica 1997;86:1275.

40 Chan V, Greenough A. Neonatal patient triggered ventilators. Br f Intensive Care 1993;216-19.

41 Bernstein G, Cleary JP, Heldt GP, Rosas JF, Schellenberg LD, Mannino FL. Response time and reliability of three neonatal patient-triggered ventilators. Am Rev Respir Dis 1993;148:358-64.

42 Milner AD, Hoskyns EW. High frequency positive pressure ventilation in neonates. Arch Dis Child 1989;64:1-3.

43 OCTAVE study group. Multicentre randomised controlled trial of high against low frequency positive pressure ventilation. Arch Dis Child 1991;66:770-5.

44 Baumer JH, Ellis S. Patient triggered ventilation in infants under 28 weeks. Early Hum Dev 1994;39:144. 